\title{
Hispanismes
}

Revue de la Société des Hispanistes Français

\section{Radicalización nacionalista en Cataluña y pacificación en el País Vasco}

Un breve análisis del tiempo presente

Radicalisation nationaliste en Catalogne et pacification au Pays basque. Une

brève analyse de l'époque actuelle

Nationalist radicalisation in Catalonia and pacification in the Basque Country. A brief analysis of the present time

\section{Mathieu Petithomme}

\section{OpenEdition}

Journals

Edición electrónica

URL: https://journals.openedition.org/hispanismes/757

DOI: 10.4000/hispanismes.757

ISSN: 2270-0765

Editor

Société des Hispanistes Français

\section{Referencia electrónica}

Mathieu Petithomme, «Radicalización nacionalista en Cataluña y pacificación en el País Vasco», Hispanismes [En línea], 16 | 2020, Publicado el 01 diciembre 2020, consultado el 31 agosto 2021. URL: http://journals.openedition.org/hispanismes/757 ; DOI: https://doi.org/10.4000/hispanismes.757

Este documento fue generado automáticamente el 31 agosto 2021.

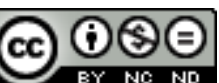

Les contenus de cette revue sont mis à disposition selon les termes de la Licence Creative Commons Attribution - Pas d'Utilisation Commerciale - Pas de Modification 4.0 International. 


\title{
Radicalización nacionalista en Cataluña y pacificación en el País Vasco
}

\author{
Un breve análisis del tiempo presente \\ Radicalisation nationaliste en Catalogne et pacification au Pays basque. Une \\ brève analyse de l'époque actuelle \\ Nationalist radicalisation in Catalonia and pacification in the Basque Country. A \\ brief analysis of the present time
}

Mathieu Petithomme

\section{Introducción}

Desde hace más de una década, en el contexto posterior a la crisis económica del 2008, un marco de referencia casi monolítico se ha impuesto en los medios de comunicación y en el espacio público, según el cual estaríamos asistiendo en Europa al auge de los «nacionalismos» y de los «separatismos». Las ideas preconcebidas, con una buena dosis de caricaturas y de tratamiento catastrofista de los acontecimientos sociales y políticos, son globalmente invariables: la mundialización y la uniformización generarían en reacción un «retorno de las identidades culturales»; la individualización de las sociedades occidentales avanzadas y la pérdida de significado vivida por los ciudadanos, favorecerían la celebración de identidades «comunitarias» alrededor de lenguas y tradiciones regionales; los «nacionalismos» constituirían un peligro para la cohesión social y territorial de las democracias liberales. Se impone por lo tanto una cadena de equivalencias según la cual los procesos de nacionalización son a priori considerados como similares: existiría un continuum que iría de reivindicaciones lingüísticas y culturales hacia demandas más políticas y económicas, hasta conseguir la autonomía, la separación y luego la independencia, presentada como el objetivo final. El paradigma del «estallido de los nacionalismos» propone así un discurso explicativo uniformador, 
casi transpuesto tal cual, para presuntamente analizar procesos sociales que presentan sin duda ciertas analogías, pero también importantes diferencias históricas y políticas.

Pero estas complejidades no importan: se trata de «trasladar» marcos de interpretación invariables y fácilmente comprensibles de un espacio cultural a otro (fracturas entre territorios del centro y territorios "periféricos» ${ }^{1}$; «nuevo egoísmo territorial» $»^{2}$ entre regiones «ricas» $\mathrm{y}$ «pobres»; rebelión de las clases populares o giro conservador, etc.), con el fin de opinar en caliente sobre procesos que son sin embargo muy distintos («Brexit»; surgimiento de la extrema derecha en Alemania; federalización de Bélgica; independentismo en Cataluña: nacionalismo en Córcega, etc.). Tomando como base una comparación de las trayectorias nacionalistas en Cataluña y el País Vasco desde 2010, este artículo muestra al contrario las especificidades políticas, sociales y culturales ampliamente infravaloradas de las trayectorias nacionalistas. Si el surgimiento de los nacionalismos es tan ineluctable, ¿cómo podemos explicar que la radicalización del independentismo en Cataluña entre 2010 y 2017 tuvo lugar al mismo tiempo que un proceso inverso de pacificación y de salida de la violencia en el País Vasco? El caso español constituye en este sentido un terreno comparativo emblemático para responder a esta cuestión teórica fundamental.

\section{Cataluña: del nacionalismo liberal al independentismo y la polarización social}

El nacionalismo catalán ha estado dominado por su corriente liberal y conservadora a lo largo del siglo XX (excepto algunos breves períodos) así como entre1980 y 2003. En la última década, se ha radicalizado. Pero el auge del independentismo ha polarizado la sociedad como nunca antes. Históricamente minoritario, el independentismo se ha cristalizado en 2010 sobre la identidad y el reconocimiento de la nación catalana, y luego en 2012, en el trasfondo de la oposición a las políticas de ajuste y austeridad. Este nuevo panorama político y social desembocó en la renovación de las peticiones históricas de autonomía fiscal. El carácter excepcional de la crisis dejó huella en las mentes: declive de los partidos que gobernaron Cataluña desde 1980 (el Partit de les Socialistas de Cataluña, PSC, y Convergència i Unió, CiU); ascenso de la izquierda independentista (Esquerra Republicana de Catalunya, ERC); declive del clivaje izquierda-derecha activado por una lista plebiscitaria (Junts Pel Sí en 2015); inestabilidad sin precedentes (4 elecciones regionales en 7 años entre 2010 y 2017).

El hecho de que el asunto de la independencia se haya convertido en el eje principal y casi hegemónico del debate político ha engendrado una movilización sin precedente del electorado: desde el 56,7\% en 2006, la participación de los ciudadanos en las elecciones al Parlamento de Cataluña ha aumentado hasta el 67,7\% en 2012, y alcanzó su máximo histórico en 2017, con un 81,9\%. Este clima de movilización y de creciente polarización del electorado se crispó también con la convocatoria de numerosas manifestaciones populares y un ambiente casi insurreccional, episodios de violencias policiales, organización de dos referéndums (9 de noviembre de 2014; 1 de octubre de 2017) prohibidos por el Tribunal Constitucional, la huida novelesca de Carles Puigdemont y de la mitad de los miembros del gobierno catalán, la suspensión temporal de la autonomía y de los poderes de la Generalitat y del Parlamento regional, y por último, el encarcelamiento y el «procés» de los principales dirigentes independentistas, considerados «prisioneros políticos» por los unos, y «separatistas» por los otros. Más 
allá de un referéndum ilegal en virtud de la Constitución de $1978^{3}$, existe un debate moral sobre la legitimidad o no de actos de desobediencia civil, una crisis identitaria y de convivencia, y un debate político y territorial sobre el futuro del Estado de las autonomías en España.

\subsection{Un nacionalismo históricamente liberal, conservador y autonomista}

A finales del siglo XIX, el «catalanismo» procedente de la burguesía y de los círculos intelectuales urbanos, se estructuró en un movimiento cultural de «normalización» de la lengua y de la identidad catalana. En un periodo más reciente, este movimiento se ha traducido desde 1980 en la petición del reconocimiento institucional de la «nación» catalana, y en la política de «inmersión lingüística» con el fin de defender el catalán como lengua vehicular. El nacionalismo catalán como proyecto político afloró en 1901 a través de la Lliga Regionalista, y constituyó, a lo largo del siglo XX, un proyecto de modernización de las instituciones españolas, más que una dinámica de separación: históricamente hablando, los nacionalistas catalanes nunca han querido salir de España sino más bien remodelar el Estado español según sus intereses ${ }^{4}$. Fracasaron en sus intentos de hacer evolucionar el Estado desde dentro hacia una forma de monarquía compuesta en el siglo XIX, y también de progresar hacia el federalismo bajo la Primera República (1873-1874). Sin embargo, obtuvieron más poderes durante la Segunda República, en 1979 y de nuevo en 2005 mediante la adopción de sucesivos Estatutos de autonomía. Una breve comparación entre la secuencia de la dictadura de Primo de Rivera (1923-1930) y de la Segunda República (1931-1939) con la actualidad (2005-2020), nos permite entender las principales características del nacionalismo catalán. No se trata aquí de presentar todos los matices y detalles de la historia, sino de subrayar tres características del nacionalismo catalán bastante estables a lo largo del tiempo.

En primer lugar, el independentismo es un fenómeno marginal, situado políticamente a la izquierda, que surge en la historia de España en los periodos de crisis política. L'Estat Català, el primer partido independentista fundado en 1922 por Francesc Macià, propuso así un proyecto de confederación española con derecho a una separación. Este partido y la corriente independentista que representaba progresaron después como una respuesta social y política a la represión de Primo de Rivera (prohibición de la lengua, de la bandera, supresión de la provincia única). La pasividad del PSOE y de la burguesía catalana de la época ayudó también a legitimar sus ideas en sectores de las clases medias urbanas, su principal apoyo social, ayer como hoy. L'Estat Català se fusionó con el Partido republicano catalán de Lluís Companys para formar, en 1931, Esquerra Republicana de Catalunya. Desde 2005, la crisis territorial y económica también ha facilitado en cierto modo la difusión del discurso territorial (independentismo) y económico (rechazo a las políticas de austeridad, giro a la izquierda) de Esquerra, en detrimento del nacionalismo liberal, conservador y autonomista representado por la Lliga a principios del siglo XX, y por Jordi Pujol y CiU desde 1980 hasta 20035: del 8,5\% de los votos en las elecciones catalanas del 1999, Esquerra progresó hasta el 16,5\% en 2006 y un $21,4 \%$ en 2017. El independentismo, históricamente de izquierdas, pero minoritario en este campo político, ha crecido de forma exponencial en los últimos quince años, ilustrando también una radicalización de los electores catalanes de izquierdas en lo que respecta a la cuestión territorial. 
En segundo lugar, el nacionalismo catalán es también plural ideológicamente, pragmático a través de la formación de alianzas políticas, deseoso de ejercer el poder en Cataluña y jugar el papel de un grupo de presión dentro del Estado español para defender y promover sus reivindicaciones estables desde el siglo XIX: reconocimiento de la identidad, de la lengua y de la nación catalanas; autonomía administrativa y política; federalismo fiscal y asimetría en la estructura territorial del Estado (más que un multilateralismo en igualdad de condiciones con las otras comunidades autónomas). De este modo, varios partidos nacionalistas (Acción Catalana, Acción Republicana de Catalunya) e independentistas catalanes (l'Estat Català) firmaron el Pacto de San Sebastián (el 17 de agosto de 1930) que permitió instituir la Segunda República con republicanos y socialistas, a cambio de la aprobación del estatuto de autonomía de 1932. Las élites catalanas de la transición aceptaron también la Constitución de 1978 a cambio del nuevo estatuto de autonomía de 1979.

En tercer lugar, los nacionalistas no quieren tanto separarse de España, como pensarse una vanguardia cuyo papel es modernizar, a través de la federalización o la confederación, un Estado español representado como políticamente débil y económicamente deficiente. Tratan de hacer evolucionar el marco constitucional a través de «momentos constituyentes» en la historia, utilizando tanto la negociación como la desobediencia civil. Los años 30 muestran también este paralelo histórico: Esquerra ganó las elecciones municipales de 1931, Macià proclamó la «República Catalana» como «Estado miembro de la Federación ibérica», y luego, renunció a la autodeterminación a cambio de la creación de la Generalitat en 1932 (con poderes en derecho civil, administración local y orden público), de un estatuto de autonomía, de la cooficialidad de la lengua catalana y de la unificación de las provincias catalanas. De manera análoga, hoy en día se trata de buscar fórmulas para que los independentistas vuelvan a entrar en el juego político convencional, con el fin de buscar un terreno de negociación y de convivencia, ya que tal y como lo mostró la represión de los años 30, la respuesta policial y judiciaria, aunque legítima, no es suficiente para resolver un conflicto político y social.

Desde la aprobación del Estatuto de autonomía de 1979 por referéndum (el 88,1\% de los catalanes votaron a favor con una participación del 59,7\%) hasta 2005, los cambios sociales fueron numerosos en Cataluña. Se puede destacar, por ejemplo, la mejora sin precedente del nivel de vida, el progreso en la igualdad de género, el aumento del nivel educativo de las nuevas generaciones, el «boom» del turismo y del sector de la construcción. Estos procesos caracterizaron la modernización de la España de los años 1980 y 1990 con un cambio de imagen radical respecto a las décadas anteriores, lo que fue simbolizado en 1992 con los Juegos Olímpicos en Barcelona: pusieron la ciudad condal en el centro del mapa mundial en una época marcada por el crecimiento económico (a pesar de la crisis de 1993) y la inserción de España en la globalización. Estos años de intenso cambio social estuvieron dominados por el PSOE de Felipe González en el gobierno de España entre 1982 y 1996, y por Jordi Pujol y CiU en Cataluña entre 1980 y 2003. Cataluña vivió entonces una importante estabilidad política alrededor de un partido dominante. Esta dominación no impidió sin embargo importantes evoluciones entre las cuales se pueden subrayar, a modo de ejemplo, las siguientes: una activa política de inmersión lingüística qué modificó los usos lingüísticos, reforzando el papel del catalán en la sociedad ${ }^{6}$; una relación estrecha entre la Generalitat, CiU y los sectores empresariales catalanes, lo que facilitó acuerdos público-privado pero también creó numerosas tramas de corrupción; o un proceso 
sociológico de integración y de cambio multicultural de la sociedad catalana a través de los flujos de inmigración de principios de los años $2000^{7}$. Ocurrieron entonces muchas cosas en el terreno del nacionalismo en Cataluña entre 1979 y 2005. Sin embargo, el periodo del predominio político de CiU mantuvo la tendencia histórica de un nacionalismo catalán principalmente liberal, conservador, moderado y autonomista. En efecto, el independentismo, sobre todo representado por ERC, permaneció una corriente política marginal: entre 1977 y 2000, ERC nunca obtuvo más del 6\% de los votos en Cataluña. Es cierto que este partido empezó a cobrar fuerza y participó en los gobiernos tripartitos de 2003 y de 2007 (cuando obtuvo el 16,4\% y el 16,5\% de los votos como tercera fuerza), pero su influencia política y en la sociedad todavía era mucho menor en comparación con su papel en la última década. En el presente artículo, nos centraremos entonces principalmente en los últimos quince años, durante los cuales se han producido los mayores cambios al respecto.

\subsection{Una radicalización del independentismo en el contexto de la crisis de 2008}

La radicalización del independentismo en el contexto de la crisis económica (2008-2014) se explica por múltiples factores: el rechazo en 2010 por el Tribunal Constitucional, después de un recurso del Partido Popular, de ciertas disposiciones del estatuto de autonomía de 2006; el surgimiento de un potente movimiento social alrededor de la Assemblea Nacional Catalana (ANC) y de manifestaciones masivas durante la Diada, la fiesta nacional catalana celebrada cada año el 11 de septiembre; asimismo, las políticas de austeridad apoyadas por CiU en Cataluña que, debilitada por los escándalos de corrupción, radicalizó por oportunismo su posición nacionalista históricamente moderada bajo el liderazgo de Artur Mas. La crisis económica favoreció el desarrollo del argumento del egoísmo fiscal («España nos roba»), en un contexto de rarefacción de los recursos de redistribución de las rentas y de declive de las solidaridades territoriales.

Para entender la dinámica del procés, es fundamental subrayar el papel de varias organizaciones surgidas desde la sociedad civil catalana. Fundada en 2005, la plataforma «Dret a Decidir» difundió poco a poco la idea según la cual los catalanes tienen derecho a decidir su propio futuro político y territorial. A partir de 2009, ERC organizó votos locales simbólicos sobre la independencia. Una nueva presión social se difundió y trató de condicionar la esfera política, apoyándose principalmente en la ANC, Ómnium Cultural, y en la Associació de Municipis per la Independència (AMI) creada en 2011 (que reúne a más del 80\% de los municipios catalanes). El activismo de 1,5 millones de personas que se manifestaron bajo el lema «La independencia, solución para Cataluña» el 11 de septiembre de 2012, también ayudó a cambiar los parámetros de la controversia. Los partidos independentistas se pusieron de acuerdo entonces para organizar una primera votación simbólica el 9 de noviembre de 2014 (sin intervención policial, fue invalidada posteriormente por el Tribunal Constitucional): movilizó 2,2 millones de electores (el 36\% del censo electoral) y desembocó en una victoria del "Sí" con un $80 \%$ de las papeletas a favor (1,8 millones de votos).

Desde la Transición, la crisis, la austeridad y los escándalos de corrupción han deslegitimado a los partidos dominantes y han radicalizado el sentimiento nacional de buena parte de los catalanes, notablemente entre los más jóvenes (18-25 años) y la generación de los jóvenes trabajadores (25-35 años). Así, detrás del auge del 
independentismo catalán, se oculta también, por consiguiente, una brecha generacional reforzada por la crisis $^{8}$, y la experiencia compartida del exilio, del paro y de la precariedad. El independentismo propone una respuesta simple, emocional y fácilmente inteligible alrededor de un proyecto de emancipación transversal (más allá del clivaje izquierda-derecha), que puede representar una forma de cambio y generar así esperanzas. La socióloga catalana Marina Subirats lo considera como una «utopía disponible», subrayando el papel de las emociones para movilizar a la ciudadanía alrededor de un nuevo ideal político ${ }^{9}$. Lo mismo ocurrió por ejemplo con Podemos en sus inicios, entre 2014 y 2016, consiguiendo movilizar a jóvenes electores de izquierdas alrededor de la posibilidad de «una nueva transición» política progresista ${ }^{10}$. El independentismo se benefició también de lo que el sociólogo Enrique Gil Calvo llamó «el efecto soufflé», íntimamente vinculado con el desgaste de los partidos y de las ideologías tradicionales en un contexto de importante volatilidad electoral ${ }^{11}$. Al contrario, sus opositores han formulado argumentos principalmente jurídicos (la falta de respeto al Estado de derecho y a la Constitución), para denigrar a aquellos que presuntamente quieren «romper España». Es cierto que los independentistas han derivado progresivamente hacia actos y discursos legitimadores de la desobediencia civil. Pero la intransigencia del gobierno conservador de Mariano Rajoy (PP), desde 2011 hasta su dimisión tras la moción de censura aprobada en el Congreso de los diputados en junio de 2018, facilitó su radicalización, ya que el ejecutivo no mostró ninguna voluntad ni tampoco capacidad de negociar o de buscar un acuerdo. Mientras el gobierno se aferraba a su posición moralizadora y poco dialogante, los independentistas ocupaban el espacio público, los medios de comunicación movilizaban a la sociedad alrededor de sus ideas, lo que contribuyó de manera decisiva a modificar la correlación de fuerzas en su favor hasta la crisis política de octubre de $2017^{12}$.

\subsection{El referéndum del 1 de octubre de 2017 y la declaración unilateral de independencia}

El referéndum del 1 de octubre de 2017 y la posterior declaración unilateral de independencia del 27 de octubre constituyeron los toques de luz del proceso de radicalización política activado desde 2010. En 2010, CiU consiguió ganar las elecciones catalanas (con un $38,7 \%$ de los votos) y Artur Mas fue investido presidente de la Generalitat el 23 de diciembre de 2010 con la abstención de los socialistas. Pero en el contexto de crisis económica que vivía entonces España, el partido de Artur Mas decretó fuertes medidas de austeridad en Cataluña que impactaron a la sanidad, la educación y los trabajadores de las administraciones públicas. El desgaste apareció claramente cuando el gobierno catalán tuvo que recurrir a un helicóptero para poder entrar en el Parlament el 15 de junio de 2011, en el contexto de las protestas del movimiento del 15-M. A raíz de estos acontecimientos y de la incapacidad de CiU de obtener del gobierno del PP un nuevo sistema de financiación para Cataluña, la posición nacionalista moderada de CiU cambió y empezó su giro independentista. La legislatura duró tan solo dos años y después de las elecciones anticipadas del 2012, CiU gobernó con ERC, que negoció su apoyo a cambio de la promesa de organizar un referéndum, lo que ocurrió en noviembre de 2014. Un año más tarde, convirtieron las elecciones al Parlamento de Cataluña celebradas en 2015, en un escrutinio plebiscitario a través de la alianza «Junts pel Sí». 
El referéndum del 2017 estuvo acompañado de numerosos actos de desobediencia civil: Pacto Nacional por el referéndum (el 23 de diciembre de 2016), ley del 6 de septiembre de 2017 sobre el referéndum, seguida de la «ley de transición jurídica y de fundación de la República» (ambas anuladas por el Tribunal Constitucional). Esta última ley preveía en caso de victoria del «Sín y sin un mínimo de participación necesaria, la organización institucional de Cataluña. El Tribunal Superior de justicia de Cataluña dio órdenes a los Mossos d'Esquadra de intervenir para recuperar las urnas y el material electoral, y oponerse así a la organización del referéndum. Los alcaldes fueron a su vez amenazados con ser inhabilitados si participaban en la organización del referéndum. Durante la Operación Anubis, la Guardia Civil detuvo a 14 altos responsables políticos del movimiento independentista. El gobierno mandó a Barcelona varios miles de guardias civiles y policías y atracó cruceros en su puerto para albergarlos y mantenerlos potencialmente disponibles durante todo el periodo del referéndum ${ }^{13}$, lo que simbolizó, de cara a los medios de comunicación, la extrema tensión política vivida. Las urnas fueron trasladadas clandestinamente desde Francia por militantes de los Comités de Defensa del Referéndum (CDR $)^{14}$, una operación descrita en el libro Operació Urnes, crónica periodística muy vendida en Cataluña, lo que muestra la fascinación causada por dicho episodio en buena parte de la ciudadanía activista ${ }^{15}$. Los independentistas ocuparon las escuelas y organizaron fiestas y comidas populares desde el viernes previo al referéndum para oponerse preventivamente al impedimento de las fuerzas de seguridad. Se encargaron de distribuir 10 millones de papeletas y consiguieron movilizar a 45.000 asesores el día del voto, ilustrando con ello un importante grado de organización colectiva.

El 1 de octubre, jornada de la votación, los Mossos d'Esquadra procedieron al cierre de 600 colegios electorales y otros 92 fueron cerrados por la Guardia Civil y la Policía Nacional (el 14\% de los colegios). Las imágenes de la violencia policial (que causó 893 heridos) dieron la vuelta al mundo y complicaron la estrategia de comunicación del gobierno conservador de Mariano Rajoy, organizada alrededor de la idea de la «ilegalidad» del referéndum, la defensa del orden y la Constitución de 1978. Según la Generalitat, la participación alcanzó el 42,4\% (2,3 millones) y un 90,1\% de los electores ( 2 millones de los 5,3) optaron por el «Sí» a la pregunta: «¿Quiere que Cataluña sea un Estado independiente en forma de república?». A pesar de la clara victoria del "Sí", del aumento de la participación y del voto independentista en comparación con los resultados de 2014, el referéndum movilizó solamente a una parte de una sociedad extremadamente dividida. El 10 de octubre, el presidente de la Generalitat, Carles Puigdemont, proclamó la independencia en sede parlamentaria, pero al mismo tiempo declaró «suspenderla» a la espera de un «diálogo» con el gobierno, que nunca tuvo lugar. Un juego de estrategia y una «batalla de comunicación $»^{16}$ se desencadenaron entonces: Mariano Rajoy le pidió "clarificar» si había efectivamente declarado la independencia, y el 21 de octubre decidió pedir al Senado la aplicación del artículo 155, que fue aprobada el 27 de octubre y que provocó la disolución de la Generalitat y del Parlamento de Cataluña, así como la convocatoria de elecciones anticipadas. El mismo día, los cargos electos independentistas aprobaron una declaración unilateral de independencia a través de un voto del Parlamento de Cataluña (que acto seguido fue declarado ilegal por el Tribunal Constitucional). Carles Puigdemont decidió huir y se refugió en Bélgica. Posteriormente miles de ciudadanos y cargos electos han sido perseguidos por la justicia por haber contribuido, de una manera u otra, a la organización del referéndum y al recuento de votos en los colegios electorales. 
Sin embargo, en las elecciones del 21 de diciembre de 2017 convocadas por el gobierno español en virtud del artículo 155, los partidos independentistas han obtenido de nuevo mayoría absoluta. El proceso judicial de sus dirigentes, ilegítimo para unos y necesario para otros, altera el juego político convencional. Acusados y condenados por el Tribunal Supremo por «sedición» en una sentencia del 12 de octubre 2019, los 9 principales dirigentes independentistas han sido encarcelados hasta ser indultados por el gobierno socialista de Pedro Sánchez el 22 de octubre de 2021: el vicepresidente catalán, Oriol Junqueras, los dirigentes de Ómnium Cultural (Jordi Cuixart) y de la ANC (Jordi Sánchez), Raul Romeva, ex responsable de asuntos internacionales, y también Carme Forcadell, expresidenta del Parlamento de Cataluña. El «procés» ha creado un verdadero problema de consciencia a la democracia española, porque el desafío no es solamente jurídico y vinculado al Estado de derecho y la Constitución, sino que se trata también de un dilema moral y de un conflicto político. ¿Hasta qué punto uno puede ser independentista en un Estado democrático? ¿Cuál es la fórmula política y territorial para salir de un conflicto que ha sido el nudo gordiano del debate social catalán y español en la última década? Las respuestas a estas dos preguntas no son sencillas, pero de ellas depende buena parte de las soluciones democráticas que se pueden barajar.

Tal y como ocurrió en 1993 con el PSOE y en 1996 con el PP, el debilitamiento de los principales partidos nacionales y la ausencia de mayorías absolutas en las sucesivas elecciones legislativas de 2015, 2016 y 2019, ha reforzado el poder de influencia de los nacionalistas: en la moción de censura contra el gobierno de Mariano Rajoy en junio de 2018, en la investidura de Pedro Sánchez y luego, en su incapacidad para aprobar los presupuestos de 2019, obligándole a convocar nuevas elecciones, en todo ello se han visto vinculados los partidos nacionalistas catalanes (junto con otros actores) condicionando en cada caso sus apoyos parlamentarios. Además, las elecciones legislativas del 28 de abril de 2019 dieron una mayoría clara a ERC en Cataluña. La salida política posterior al «procés» y el encarcelamiento todavía vigente de los dirigentes independentistas, dificultan la salida de la crisis. Más allá de la independencia necesaria de la justicia y del respeto absoluto de sus decisiones, el conflicto político se podrá solucionar solamente de manera análoga a las crisis históricas anteriores: es decir, por la negociación y la federalización, por una reforma de la autonomía catalana y del marco institucional del Estado de las autonomías. Solo una solución de compromiso puede permitir crear una nueva hegemonía social más allá del estatus quo y del independentismo.

\section{País Vasco: de la violencia política a la pacificación}

Tras decretar unilateralmente el «cese definitivo de la lucha armada» el 20 octubre de 2011, Euskadi Ta Askatasuna (ETA, «País Vasco y Libertad») refrendó la evolución progresiva del nacionalismo vasco radical desde los años 2000 marcada por un giro hacia la defensa de un independentismo democrático, pasando a participar plenamente en el juego electoral e institucional. El nacionalismo vasco «radical» es considerado como tal en la medida en que promueve «un objetivo revolucionario tratando de atacar el poder del Estado según una ideología de cambio social radical» ${ }^{17}$. En cambio, el independentismo es solamente un ideal político. Puede ser defendido democráticamente o saltándose la ley, pero los medios utilizados son independientes de su ideología. 
Después de haber causado la muerte de más de 843 civiles, policías, militares o responsables públicos entre 1968 y 2010, esta evolución ilustró también el desmantelamiento por el Estado de derecho y merced a la represión policial, del aparato militar de ETA. Más allá de ETA, de sus organizaciones satélites, de las formaciones políticas y de las diferentes «marcas» de la izquierda «abertzale», el nacionalismo vasco radical constituye sin embargo un potente movimiento social, cuyo anclaje en la sociedad permite explicar su persistencia hasta nuestros días. Por movimiento social, entendemos las acciones colectivas de una comunidad política que comparte un sistema de valores y un sentido de pertenencia, y que goza también de una capacidad de movilización en el espacio público alrededor de reivindicaciones, adversarios y de un proyecto político y social propio ${ }^{18}$. Tras un breve análisis de los principales repertorios de acción del nacionalismo radical, en esta parte se sintetizarán las mayores evoluciones de esta corriente política en la última década, desde la salida de la violencia hasta el proceso contemporáneo de pacificación, poniendo especial énfasis en los asuntos todavía pendientes. Mostraré cómo la trayectoria del nacionalismo vasco, y más específicamente del nacionalismo radical, ha sido muy diferente de la evolución del nacionalismo catalán a pesar de un contexto nacional similar, marcado por una década de crisis económica, política y social.

\subsection{Una variedad de repertorios de acción colectiva}

Por nacionalismo vasco radical, se puede entender la versión más intransigente del nacionalismo vasco, vinculada históricamente con el entorno de ETA entre 1958 y 2011. El nacionalismo vasco radical se autoproclama como el representante legítimo de la nación vasca en su totalidad (incluyendo Euskadi, el País Vasco francés y Navarra), y reivindica su derecho a la autodeterminación. Las manifestaciones callejeras constituyen un repertorio de acción colectiva clave para la izquierda «abertzale» ${ }^{19}$ («patriota»). Desde los años 1960 hasta la actualidad, los nacionalistas radicales han organizado numerosas acciones colectivas en favor de la amnistía de los presos de ETA, a los que consideran «presos políticos». De este modo, celebran ceremonias en honor de los «gudaris» («combatientes») 原un término inicialmente usado para designar a los soldados vascos y republicanos que lucharon contra las tropas franquistas durante la Guerra Civil厦, un acto que ha sido desviado durante las fiestas populares del Bizkargi Eguna y del Albertia Eguna para homenajear a los «mártires de ayer y de hoy», presentando así a los militantes de ETA como los herederos históricos de los soldados de la Guerra Civil ${ }^{20}$. El nacionalismo radical se ha apropiado también de los cantos tradiciones del Agur Jaunak o de la Marcha Fúnebre Gernika, en el sentido en que su uso repetido por los actores radicales ha vinculado estos cantos a esta corriente política, utilizándolos políticamente para justificar y legitimar sus objetivos.

En efecto, la memoria juega un papel central en el proceso de formación de una identidad y de invención de las tradiciones de un grupo social" ${ }^{21}$. A partir de la iniciativa del PNV, el Bizkargi Eguna ${ }^{22}$ y el Albertia Eguna ${ }^{23}$ conmemoraban inicialmente la memoria de los combatientes vascos muertos durante la Guerra Civil, así como la defensa del territorio frente a la insurrección franquista. Estas festividades constituyen celebraciones «vascas»: incluso si los nacionalistas 医demócratas-cristianos o radicales蓲 son los más apegados a ellas, forman parte de la historia y de la memoria colectiva del País Vasco. Por lo tanto, estas dos fechas históricas jugaban inicialmente un papel integrador en la sociedad vasca, mientras permanecían despersonalizadas 
porque celebraban la memoria de los resistentes vascos en general sin establecer el culto a personalidades particulares. Homenajeando a los «mártires» y a los presos de ETA, los nacionalistas radicales han desviado el significado inicial que el PNV había dado a estos eventos colectivos. De hecho, las corrientes moderadas y radicales del nacionalismo vasco organizan sus propias celebraciones, ilustrando con ello un proceso de concurrencia por la memoria que implica cómo "grupos que dan significados distintos a un mismo evento se disputan para obtener el monopolio de un lugar de memoria $»^{24}$. Cuando aludo a desviar el significado inicial, me quiero referir a «la generación y la difusión de una historia alternativa» de la lucha independentista ${ }^{25}$. En efecto, para legitimar su lucha, «el movimiento tiene que ser capaz de ponerla en escena, a través de un trabajo de manipulación simbólica, con el fin de reforzar el compromiso activista ${ }^{26}$. En este sentido, la memoria de los combatientes de la Guerra Civil constituye un «recurso político» para el nacionalismo radical porque su reapropiación favorece la legitimación y la persistencia de una estrategia de resistencia radical. Insertar simbólicamente el compromiso de los miembros de ETA en la historia de la lucha y del nacionalismo vasco, permite revalorizar sus roles controvertidos y aportarles un reconocimiento social.

También a cada salida de prisión de un miembro de ETA las Gestoras pro-amnistía organizaban ceremonias triunfales de recibimiento. Estas manifestaciones recurrentes de simpatía, sinónimo para muchos de enaltecimiento del terrorismo, han generado una enorme controversia política y social. Sin embargo, dichas celebraciones también han mostrado la cohesión social, el rechazo a la estigmatización y la transmisión familiar de una memoria de la lucha política en el seno de la comunidad nacionalista radical. De otro modo, durante los años 1990, la «kale borroka», la lucha callejera, fue también utilizada por jóvenes radicales que, combinando pasamontañas, tirachinas y cócteles Molotov, trataron de provocar enfrentamientos violentos con las fuerzas de seguridad. Disturbios que tenían un objetivo performativo, es decir, que buscaban «representar» el «conflicto vasco» a través de actos violentos que le hacían existir. Los objetivos del nacionalismo vasco radical, - la autodeterminación, la amnistía y la expulsión de las fuerzas armadas del País Vasco mediante la lucha armada, las urnas y las manifestaciones -, prácticamente no ha variado desde 1958. Solo los medios utilizados han evolucionado con el cese definitivo de la lucha armada en 2011. De manera esquemática, inspirándose de Gaizka Fernández Soldevilla y Raúl López Romo, es posible distinguir cuatro fases distintas en la trayectoria contemporánea del nacionalismo vasco radical: la «resistencia» al régimen franquista (1958-1977); la monopolización del espacio público (1978-1994); el declive de su hegemonía movilizadora (1995-2011) ${ }^{27}$, y la institucionalización del nacionalismo radical en el juego electoral desde 2011.

Desde entonces, asistimos en efecto a una forma de «transición democrática» del nacionalismo vasco radical, caracterizada por el rechazo formal de la violencia y el inicio de una autocrítica sobre los años de lucha $\operatorname{armada}^{28}$. El nacionalismo radical legitimaba en los años 1980 la violencia, y luego durante los años 90, formuló numerosos eufemismos para no condenarla. La sacralización de sus postulados (la autodeterminación, la pertenencia del País Vasco francés, de Navarra y de Euskadi a la misma nación, la retirada de la Guardia Civil y de las fuerzas armadas del País Vasco), crearon un tipo de "religión política» ${ }^{29}$ legitimando la desobediencia civil, pero ejerciendo sobre todo la violencia, negando al otro la libertad de expresión que los nacionalistas radicales revindicaban para ellos. La postura antisistema (aunque ahora 
están plenamente inmersos en el sistema) y el populismo - evocando constantemente actuar en nombre del "pueblo» vasco - prácticamente no han cambiado. Tampoco ha cambiado el frecuente uso de las manifestaciones callejeras. Esta corriente política ha conseguido fidelizar a una amplia base militante, muy implicada políticamente y activa en la sociedad vasca, pero que se encuentra desde ahora en adelante en un proceso de inserción definitiva dentro del juego democrático y electoral. Si bien es cierto que durante los años 1980-1990 existió una retórica que criticaba el «terrorismo de Estado», y que todavía se mantiene una crítica a la «violencia de Estado» a la que supuestamente está sometido el País Vasco en la actualidad, la renuncia a la lucha armada no es solamente un hito histórico, sino también un progreso social sin precedentes. Este proceso, resulta sin embargo incompleto y está sujeto a numerosas tensiones dentro de la comunidad nacionalista radical.

\subsection{Una ruptura con el pasado: Fin de la violencia, renovación del independentismo y pacificación}

En octubre 2010, varios antiguos responsables de Batasuna, entre ellos su exdirigente Arnaldo Otegi, encarcelado desde 2009 a 2016 por una presunta colaboración con ETA, han incitado a la organización armada a proclamar un alto el fuego unilateral y un rechazo incondicional de la violencia sin exigir prerrequisitos al gobierno español. La izquierda «abertzale» consideró entonces el comunicado de ETA de octubre de 2011 como una evolución «histórica». El nacionalismo radical efectuó paralelamente un importante retorno al escenario electoral: con el $25 \%$ de los votos y 21 representantes de los 75, Euskal Herria Bildu («Reunir Euskal Herria», EH Bildu), una coalición compuesta por los partidos Sortu, Eusko Alkartasuna, Aralar y Alternatiba, se confirmó en 2012 en el Parlamento vasco como la segunda fuerza política detrás del Partido Nacionalista Vasco (PNV). Durante las elecciones municipales de 2011, Bildu obtuvo un $26,3 \%$ de los votos detrás del PNV (30,7\%), aunque sus votos, más territorialmente concentrados en las zonas vascohablantes y en Guipúzcoa, le han permitido obtener 953 concejales municipales frente a los 873 del PNV ${ }^{30}$. La coalición conquistó entonces San Sebastián y nombró alcalde a Juan Carlos Izagirre. Bildu, una coalición formada el 3 de abril de 2011, pasó a ser EH Bildu en 2012. A pesar de la nueva competencia política representada por Podemos (que obtuvo entonces el 14\% de los votos), las elecciones vascas de 2016 reafirmaron el dominio del PNV (37\%), pero también el arraigo social de los independentistas alrededor de EH Bildu (21\%).

Diez años después de la sentencia ilegalizando Batasuna, y después de haber presentado ocho «marcas» electorales distintas, el 23 de febrero de 2013, el Congreso constituyente de Sortu en Pamplona marcó el inicio de una nueva era para el nacionalismo vasco radical. El partido llamó a «romper las cadenas con Francia y España y a participar en la ola en favor de la independencia» ${ }^{31}$. Sortu y EH Bildu trataron de convencer al PNV, un partido nacionalista democratacristiano de posiciones moderadas, en la creación de un frente independentista en torno al «derecho a decidir». En Irún, el 24 de enero de 2015, Sortu propuso una «insubordinación democrática» a través de un proceso «unilateral y desobediente» que podría desembocar en una «Constitución de la República vasca» ${ }^{32}$. El partido trata de ampliar la base social del independentismo, multiplicando para ello las organizaciones políticas, sindicales y culturales afines con sus objetivos. También se plantea la creación de «nuevas mayorías sociales para utilizar las instituciones existentes al servicio de la soberanía», y para luego poder redefinir desde abajo los 
modelos políticos y jurídicos de Euskadi, del País Vasco francés y de Navarra, según tres procesos distintos con sus propios ritmos, pero con un mismo fin: construir un Estado vasco independiente ${ }^{33}$.

Aunque el discurso ha cambiado y Sortu y EH Bildu rechazan claramente la lucha armada en sus estatutos, los antiguos miembros de Batasuna, Rufi Etxebarria, Joseba Permach y Juan José Petrikorena controlan el Consejo Nacional de Sortu, ilustrando una cierta continuidad de los máximos dirigentes. Arnaldo Otegi jugó un papel central en la evolución de la estrategia de los independentistas ${ }^{34}$, sosteniendo la «construcción de una mayoría social» a través de un «frente soberanista» con el PNV. En enero de 2014, la manifestación común de la izquierda abertzale junto con el PNV mostró un acercamiento entre las dos franjas tradicionales del nacionalismo vasco. Pero en la práctica, el PNV prefiere más bien aislar a la izquierda abertzale y mantenerla en la oposición que gobernar con ella: en las tres últimas elecciones vascas $(2012,2016$ y 2020), el PNV y EH Bildu tuvieron al alcance una mayoría absoluta nacionalista, pero el PNV siempre se ha negado a dar tal paso prefiriendo gobernar en minoría como ocurrió en 2012 y con el apoyo del Partido socialista de Euskadi desde 2016. De este modo, el $27 \%$ de los votos y los 21 diputados regionales obtenidos por EH Bildu en 2020 no le han bastado para acceder al gobierno vasco.

Aunque los independentistas han logrado gobernar pueblos, ciudades y metrópolis, solos o con el apoyo externo del PNV, no consiguen arrebatarle el dominio político del Gobierno vasco, un poder institucional íntimamente vinculado y dominado desde la Transición y casi ininterrumpidamente por el PNV. La «lucha ideológica» y la «confrontación democrática» en la calle y en las urnas siguen constituyendo los principales pilares de su estrategia política. Pero la izquierda «abertzale» tiene varios puntos débiles que le impiden conseguir su ideal político: se la vincula a la izquierda, y más precisamente a una parte radical de la izquierda, lo que la impide llegar a una hegemonía social, contrariamente al PNV al que se le considera como el representante del «elector medio»; defiende representar a los vascos de Navarra y del País Vasco francés, cuando en la práctica una parte importante o mayoritaria de los ciudadanos de estos dos territorios no se sienten representados por esta corriente política; y por último, aunque las posiciones de sus representantes están cambiando debido en parte al acceso a los poderes locales, todavía sigue teniendo un ethos de movimiento de oposición. A pesar de su encarcelamiento entre 2009 y 2016 por el caso «Bateragune», los militantes de Sortu eligieron a Arnaldo Otegi como secretario general tras su congreso fundacional el 23 de febrero de 2013 (un cargo que quedó vacante mientras permaneció en prisión). Este hecho demostró que la salida de prisión de los presos de ETA y el fin de numerosos juicios por colaboración presumida con ETA o presuntas declaraciones de enaltecimientos del conflicto, siguen constituyendo desde el punto de vista de esta corriente política asuntos sin resolver ${ }^{35}$. El propio Otegi salió de prisión el 1 de marzo de 2016 tras cumplir íntegramente la pena de prisión de una condena que fue posteriormente anulada en 2018 por el Tribunal Europeo de Derechos Humanos y en 2020 por el Tribunal Supremo, al considerar que el juicio no fue justo por la falta de imparcialidad de la magistrada que presidía el tribunal de la Audiencia Nacional. Delante de más de 2000 militantes en Irún en enero de 2015, el portavoz del Consejo nacional de Sortu, Pernando Barrena, declaró así que «la política de represión del Estado español aún no ha terminado», lo que se demuestra por «su política penitenciaria criminal» (y más precisamente por la política de «dispersión» de los presos vascos en toda España). 
En el plano organizacional, el nacionalismo vasco radical ha mantenido la tradición de la creación de una multiplicidad de grupos políticos afines, organizándose en círculos concéntricos alrededor del núcleo central. Esta estrategia le permite multiplicar los actores y los niveles de discurso, así como desarrollar su impacto social: Amaiur, Bildu, Sortu y más recientemente Euskal Herria Bildu son sucesivas marcas electorales que han tratado de aglutinar y ampliar el espacio político de la izquierda «abertzale». En la actualidad, la coalición EH Bildu reúne tres partidos (Eusko Alkartasuna, Sortu y Alternatiba) más los antiguos miembros de Aralar (2007-2012) e independientes. La existencia de varias tendencias dentro de EH Bildu explica las divergencias que pueden existir como, por ejemplo, la mayor insistencia de algunos militantes en el discurso anticapitalista o posiciones más cercanas a los movimientos sociales, al tercer sector y al cooperativismo asociativo y empresarial (muy desarrollado en el País Vasco). El hecho de que ciertos actores defiendan posiciones más moderadas mientras otros justifican la desobediencia y actos anticonvencionales forma parte de su estrategia.

Pero la democratización interna de la coalición, que pretende optar por la «democracia participativa», queda limitada. Si bien es cierto que más de 6000 personas han participado en su Congreso constituyente, lamentablemente, solo algunas candidaturas estuvieron abiertas al pluralismo: los militantes tuvieron que ratificar en cierta medida las candidaturas únicas presentadas por la dirección. Hasier Arraiz fue nombrado presidente, Idoia Aiastui, responsable de organización, y Arnaldo Otegi, secretario general, a pesar de su encarcelamiento. Después de que Podemos lograra la victoria en Euskadi durante las legislativas de 2015 y 2016, Hasier Arraiz pidió una reorganización más allá de una coalición de partidos y una «nueva cultura de participación» que permitiera a los militantes «decidir por sí mismos». Fragmentado, el nacionalismo vasco radical también sigue impregnado de una cultura política que valoriza en su funcionamiento interno una vertical del poder, lo que influye en la nominación de sus portavoces y de sus representantes territoriales. Finalmente, su estrategia de competición sigue estando influenciada por una visión conflictiva de la política.

\subsection{Una transición inacabada}

Otros eventos muestran que la transición de esta corriente política no se ha acabado. El 23 de septiembre de 2011, el "Colectivo de los presos políticos vascos» (EPPK), que agrupaba entonces 732 presos de ETA, publicó un comunicado apoyado por el $90 \%$ de sus miembros, en el cual respaldaba el Acuerdo de Guernica del 25 de septiembre de 2010 sobre el fin de la violencia y se comprometía a «avanzar en el proceso democrático», al mismo tiempo que pedía un proceso de negociación entre la organización y el gobierno ${ }^{36}$. Los presos considerados como «disidentes» por la organización (que, en su mayoría, han sido expulsados de ella), agrupados en el "Colectivo de los presos implicados con el proceso de paz irreversible», emitieron el mismo día otro comunicado apoyando el Acuerdo de Guernica, pero llamando también al «reconocimiento del sufrimiento causado a las víctimas, y a la reconciliación social» ${ }^{37}$. En 2012, solamente una treintena de presos había elegido la vía Nanclares que facilita la obtención de reducciones de penas para aquellos presos que rechacen la violencia y asuman de manera crítica su pasado y su pertenencia a ETA.

La decisión del Tribunal Europeo de derechos humanos de julio de 2012, que consideró abusiva la detención de Inés del Río, puso fin a la doctrina Parot y permitió la liberación de 71 presos de ETA ${ }^{38}$. También puso encima de la agenda política la cuestión de su 
reinserción social. El Foro Social creado en 2013, intenta obtener el fin de la política de dispersión penitenciaria y la liberación de los presos. Los presos, las asociaciones que les defienden, así como sus entornos familiares, constituyen grupos de presión y actores centrales del proceso de pacificación. Por ejemplo, tras una convocación de $\mathrm{EH}$ Bildu y de los sindicatos nacionalistas ELA y LAB celebrada el sábado 17 de enero de 2015 más de 100.000 personas se manifestaron en San Sebastián para protestar contra la operación Mate llevada a cabo por la Guardia Civil y en la que se detuvieron a doce abogados de los presos de ETA. El lema de la manifestación, «Derechos humanos. Solución, Paz», ilustra perfectamente cómo los nacionalistas radicales presentan la causa como una lucha legítima de los «presos políticos», y por consiguiente, como una lucha por los derechos humanos y por la paz. El 25 de febrero de 2015, Íñigo Urkullu fue el primer lehendakari (presidente de la comunidad autónoma de Euskadi), en recibir de manera oficial a las familias de presos de ETA durante una reunión con Maider Alustiza, la portavoz de Etxerat, una asociación que les representa.

Además, está claro que el discurso de esta corriente política es todavía «radical» - en el sentido en que defiende una «hipótesis revolucionaria»" ${ }^{39}$, lo que crea un clima de tensión con las otras formaciones políticas y desemboca en numerosos procedimientos y sentencias judiciales contra sus dirigentes. Lo que quiero señalar aquí es el proceso de juridificación de la política (las sentencias por enaltecimiento del terrorismo se han multiplicado por cuatro desde el cese de la violencia en 2011) ${ }^{40}$, que dificulta en cierta medida la normalización del conflicto político vasco, recreando permanentemente una estructura de enfrentamiento entre «víctimas» y presuntos responsables (de humillación a las víctimas, etc.). Este proceso muestra también las dificultades de los dirigentes de esta corriente política en defender sus derechos a la libertad de expresión, por muy radicales que sean. Por ejemplo, en octubre de 2013, Hasier Arraiz increpó a Borja Sémper, el portavoz del PP en el País Vasco, llamándole «fascista». El 18 de diciembre de 2013, durante una ceremonia de homenaje a Santiago Brouard y Josu Muguruza, dos dirigentes de Herri Batasuna asesinados por los GAL, en 1984 y 1989 respectivamente, el mismo Arraiz declaró que «la única violencia es la ejercida por el Estado terrorista y la Guardia Civil», y reivindicó la trayectoria histórica del partido a pesar de sus anteriores vínculos con ETA ${ }^{41}$. Convocado por el Tribunal Supremo de justicia del País Vasco por un presunto delito de apología del terrorismo y de humillación de las víctimas a raíz de una denuncia de la asociación Dignidad y Justicia, Arraiz declaró haber defendido la estrategia de la izquierda abertzale de los 35 últimos años que consistía en «romper con España», pero no «la lucha armada de ETA» ${ }^{42}$. Fue finalmente absuelto, pero según él, su convocación ilustraba «la falta de libertad de expresión de los militantes independentistas». Otro ejemplo fue la utilización política por parte de Sortu, de la manifestación conjunta con el PNV de 2014 en favor de los presos, que se terminó con gritos a favor de ETA, e ilustró perfectamente el camino que aún queda por recorrer.

Todos estos episodios no son epifenómenos, sino que demuestran que, a pesar de que los estatutos de Sortu y de EH Bildu condenan la violencia, los discursos o las prácticas de algunos militantes independentistas pueden ser ambiguos, y la condenación explícita de los años de lucha armada sigue siendo un tabú para este sector social. Hay que reconocer que no son los dirigentes políticos quienes ensalzan a ETA en algunas manifestaciones (como los homenajes a presos de ETA a su salida de prisión o las celebraciones de los «mártires» de la organización), de tal manera que no se les puede considerar responsables. La retórica del antifascismo es también una posición política 
que se puede defender en democracia, y la izquierda abertzale no tiene el monopolio de su uso (vinculado con la extrema izquierda), si pensamos por ejemplo en algunas declaraciones de dirigentes de Unidas Podemos o de la CUP en Cataluña. Es también cierto que el nacionalismo vasco radical, debido a su antiguo vínculo con ETA, es la corriente política más estigmatizada en España, lo que se traduce en numerosos juicios en su contra. En muchos de ellos, sus actores finalmente quedan absueltos, lo que demuestra una alta juridificación de la política vasca y española, une tendencia nefasta para el funcionamiento ideal de las instituciones democráticas.

\subsection{Los asuntos pendientes: autocrítica y reconciliación}

Como conclusión diremos que el nacionalismo vasco radical se encuentra actualmente en una encrucijada. Por una parte, condena cada vez más la lucha armada pasada y también las derivas de la «kale borroka». Son cada vez más frecuente las condenaciones de los disturbios callejeros por parte de dirigentes de esta corriente política, algo que nunca ocurrió en el pasado. El dirigente de Sortu, Joseba Permach, declaró por ejemplo su «rechazo absoluto» al ataque contra el cuartel general del PP de Barakaldo en noviembre 2013, llamando a sus simpatizantes a defender los derechos de los presos de ETA «con métodos pacíficos». En 2012, dirigentes de Bildu también participaron en el homenaje a los parlamentarios socialistas Fernando Buesa y Enrique Casas, lo que significó el inicio de un reconocimiento del dolor causado por la lucha armada. Por otra parte, la autocrítica sobre el uso del terrorismo sigue siendo tabú dentro de la comunidad radical: en efecto, sus representantes y militantes tratan de poner sistemáticamente a «todas las víctimas» en el mismo plano, dando así a entender que los miembros de ETA asesinados por las fuerzas de seguridad tienen que ser recordados de la misma manera que las víctimas de la organización. Bildu se negó por ejemplo a participar en 2013 al homenaje a las víctimas, apoyado por todas las otras fuerzas políticas, y celebrado desde 2009 en Getxo durante el «Día de la memoria». En términos generales, trata de formular una visión alternativa de la historia y de la memoria colectiva en el País Vasco, movilizando a sus seguidores alrededor de «mártires», fechas y ceremonias propias, con el fin de preservar la cohesión social del grupo radical y favorecer la transmisión generacional de su lucha política.

Sin embargo, cabe señalar que la democratización de esta corriente política aún está en camino. Por democratización, no me estoy refiriendo solamente aquí al hecho de concurrir a las elecciones, respetar las normas del juego y declarar que no acepten la violencia. Desde esta perspectiva meramente institucional, el nacionalismo vasco radical, nos guste o no sus postulados ideológicos, es hoy en día una fuerza política democrática. Me refiero precisamente al proceso social de salida de la violencia, lo que implica importantes cambios a nivel sociológico en la deslegitimación de la violencia y de discursos justificando el odio, o en la gestión de la memoria histórica. Una democratización inacabada significa también que los discursos y las posiciones de los dirigentes han cambiado claramente, pero que no siempre es el caso de los militantes de a pie, y menos aún de algunos antiguos presos de ETA que siguen sin arrepentirse ni lo quieren hacer. Con razón se les pide a los antiguos miembros de ETA que se arrepientan por la lucha armada. Pero notamos también que ni el PSOE ni el PP han reconocido a las víctimas causadas por el terrorismo de Estado de los GAL, a pesar de los asesinatos cometidos por los mismos con el consentimiento implícito del gobierno del PSOE entre 1983 y 1987. 
En los pueblos del País Vasco, los descendientes de las víctimas de ETA viven cotidianamente al lado de los antiguos miembros de la organización que han salido de prisión. Algunos se odian claramente, otros se dan a menudo la espalda, pero los que se hablan son cada vez más numerosos. Se han creado foros de encuentros y de reconciliación, ayudando con ello al perdón y a la convivencia mientras que la palabra pública se ha liberado durante la última década. La misma dinámica también se puede observar en los consejos municipales, donde los representantes de EH Bildu participan en las decisiones políticas locales. Confrontaciones reales o simbólicas surgen aquí y allá. Los independentistas no dudan en retirar la bandera española del frontón de las alcaldías y de vez en cuando, toman decisiones o emiten comunicados que ilustran prácticas de desobediencia civil. Sin embargo, también modifican sus planteamientos frente a las necesidades de adaptar su "gestión» municipal (más inclusiva que su retórica), y con el objetivo de satisfacer a sus electores que no siempre son independentistas. Los que viven en el País Vasco son unánimes en decir que desde 2011 las cosas han cambiado claramente. El clima social es más sereno y la pacificación progresa, debido en buena parte a la ayuda de las nuevas generaciones, cuyas actitudes y deseos han cambiado. Desde el final de ETA, las fuerzas de seguridad son menos numerosas, lo que transmite una mayor tranquilidad.

Estas tendencias también se pueden comprobar a partir del clima de la opinión pública. Por ejemplo, según el Euskobarómetro de mayo del 2018, el 67\% de los vascos reafirman su rechazo al terrorismo de ETA, una posición compartida mayoritariamente tanto por los nacionalistas $(58 \%)$ como, sobre todo, por los no nacionalistas $(77 \%)^{43}$. Del mismo modo, la inmensa mayoría de los vascos $(88 \%)$ consideran que «se debe hacer justicia con las víctimas de ambos bandos» y un 76\% están de acuerdo con la idea de que «ETA y sus activistas deben reconocer el error de su historia de violencia y arrepentirse de su pasado». Sin embargo, ilustrando nuestra tesis de un cambio notable, pero a la vez de una transición inacabada, el consenso se rompe alrededor de la idea según la cual «ETA ha sido la principal responsable de la violencia vivida en el País Vasco»: mientras el 62\% de los no nacionalistas aprueban esta idea, el 59\% de los nacionalistas la desaprueban (y hasta el $62 \%$ de los electores de EH Bildu). De manera general, el reconocimiento del daño causado, de sus errores y la petición de perdón por parte de ETA siguen dividiendo a la sociedad vasca. Una minoría, aunque creciente (un 46\%, 11 puntos más que en 2016), de la sociedad sigue decantándose por el apoyo a medidas que permitan una reinserción social a todos aquellos terroristas que se arrepientan y que expresen su decisión de abandonar las armas. Poco a poco, cada uno acepta el juego de la democracia y de la reconciliación, reconociendo la necesidad del diálogo y del compromiso en una sociedad vasca plural, una característica constante desde finales del siglo XIX.

\section{Conclusión}

Está claro que las respectivas historias del nacionalismo catalán y vasco son complejas, diversas y llenas de matices. Las importantes similitudes históricas entre los movimientos nacionalistas vasco y catalán están hoy en día bien documentadas: emergencia a finales del siglo XIX en un contexto de industrialización naciente en el País Vasco y acabada en Cataluña; evoluciones lingüísticas y culturales, a través del renacimiento cultural en Cataluña («Renaixença») formando parte del nacionalismo 
romántico propio de mediados de siglo, y mediante la inmigración masiva en el País Vasco procedente de otros territorios de España, lo que reforzó el uso del castellano en la sociedad al mismo tiempo que el euskera declinaba; experiencias compartidas de la represión cultural y lingüística durante el franquismo; reivindicaciones históricas de defensa de sus lenguas propias y de su autonomía reconocidas por los estatutos de autonomía de 1932 y 1979; transferencias masivas de competencias desde los años 1980, dando largas prerrogativas a los gobiernos autonómicos en materia de policía, de educación y de salud. Pero las divergencias son también numerosas entre un nacionalismo y el otro: existencia de una franja más radical del nacionalismo en el País Vasco, lo que se ha traducido en la legitimación de la violencia política a través de ETA, mientras en el caso catalán el nacionalismo siempre ha sido más moderado, heterogéneo ideológicamente, liberal y autonomista al menos a lo largo del siglo XX; prácticas lingüísticas más segregadas en el País Vasco versus políticas de «inmersión lingüística» y bilingüismo de hecho en Cataluña; uso y legitimación de la violencia por una parte de la sociedad vasca versus inexistencia de movimientos violentos en Cataluña (salvo algunos grupúsculos ${ }^{44}$ ); mantenimiento casi ininterrumpido (excepto entre 2009 y 2012 ${ }^{45}$ de la dominación institucional de un partido nacionalista moderado (PNV) versus declive progresivo a partir de 2003 del partido nacionalista (CiU) dominante en Cataluña en los años 1980 y 1990, etc. Se podría haber imaginado que los efectos de la «Gran Recesión» en España entre 2008 y 2015 hubieran sido similares sobre la renovación de las reivindicaciones nacionalistas, pero esto no ha sido el caso, ni mucho menos.

Para concluir este artículo, es necesario dar algunas pistas de explicación de estas trayectorias divergentes. Primero, el impacto de la crisis ha sido mucho mayor en Cataluña, tanto respecto al endeudamiento de la comunidad autónoma (que llegó a ser casi insostenible durante el verano de 2012), como en sus impactos sociales (fuerte aumento del paro, medidas de austeridad más drásticas, etc..). En cierta medida, el Estado de bienestar vasco, el que más recursos tiene en España junto con el de Navarra, protegió mejor a sus ciudadanos durante la crisis. Además, hay que añadir otros factores institucionales (una financiación autonómica más favorable que la de Cataluña, basada en el privilegio de los fueros históricos, todavía vigentes tanto en Navarra como en el País Vasco), pero también culturales y endógenos (tal y como la «excepción» vasca respeto a los casos menos frecuentes de corrupción vinculados con la élite política y la administración local). Estos factores, así como el impacto diferenciado de la crisis económica, han generado una difusión mucho más extensa de las reivindicaciones de autonomía fiscal en Cataluña (los vascos no pueden «pedir» tal autonomía porqué ya la tienen).

Por último, las trayectorias de los movimientos nacionalistas han estado vinculadas estrechamente a sus propias historias contemporáneas, anteriores a la crisis de 2008. Hay que recordar que fue el rechazo del Congreso de los diputados al Plan Ibarretxe en

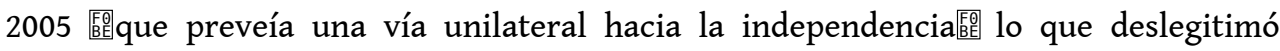
posteriormente esta opción política en el País Vasco. Deslegitimó también el «frente soberanista» que se creó a través del acercamiento entre Herri Batasuna y el PNV después del Pacto de Estella en 1998. Esta coyuntura explica incluso en la actualidad el acercamiento posterior del PNV al PSE-EE y el recelo del primero en pactar de nuevo con los independentistas. Al contrario, en el caso catalán, la aprobación del estatuto de autonomía de 2006 y el rechazo posterior por el Tribunal Constitucional en 2010 de algunos de sus avances más emblemáticos, activó la radicalización de una parte de la 
sociedad catalana. En el País Vasco, después de una generación militante marcada por la violencia (de 1975 hasta principios de los noventa), y otra por la «kale borroka» y la lucha callejera (de 1990 hasta los años 2000), las nuevas generaciones nacionalistas buscan hoy la inclusión del independentismo en el juego político. En Cataluña, por su parte, asistimos desde 2010 a una radicalización de la juventud alrededor del ideal independentista. Las trayectorias nacionalistas divergentes de radicalización en Cataluña y de pacificación en el País Vasco se explican por consiguiente por un cúmulo de factores económicos, institucionales, culturales, históricos y políticos que rehabilitan, contrariamente a ciertas tendencias mediáticas de nuestra época, la necesidad de estudiar la historicidad de las sociedades políticas.

\section{BIBLIOGRAFÍA}

Adrián ALMEIDA DIEZ, «La hipótesis revolucionaria. Nacionalismo vasco y crítica a la modernidad», Araucaria. Revista Iberoamericana de Filosofía, Política, Humanidades y Relaciones Internacionales, año $22, n^{\circ} 43$ (2020), p. 119-142.

Jean Thomas ARRIGHI DE CASANOVA, «Managing Immigration in a Multinational Context. Border Struggles and Nation-Building in Contemporary Scotland and Catalonia», Eve Hepburn y Ricard Zapata-Barrero (eds.), The Politics of Immigration in Multi-level states, Londres, Palgrave Mac Millan, 2014, p. 108-129.

Antoni BATISTA, Adiós a las armas. Una crónica del final de ETA, Madrid, Debate, 2011.

Jesús CASQUETE, «Abertzale sí, pero, ¿quién dijo de izquierda?», El Viejo Topo, n 268 (2010), p. 14-19. Jesús CASQUETE, «La religión de la patria», Claves de Razón Práctica, n²07 (2010), p. 40-46.

Jesús CASQUETE, En el nombre de Euskal Herria. La religión política del nacionalismo vasco radical, Madrid, Tecnos, 2009.

Montserrat CLUA I FAINÉ, «Identidad y política en Cataluña: el auge del independentismo en el nacionalismo catalán actual», Quaderns-e de l'Institut Català d'Antropologia, vol. 2, n 19 (2014), p. 79-99.

Laurent DAVEZIES, Le nouvel égoïsme territorial, Paris, Le Seuil, 2015.

Arnaud ESQUERRE et Gérôme TRUC, «Les morts, leurs lieux et leurs liens», Raisons Politiques, $\mathrm{n}^{\circ} 41$ (2011), p. 5-11.

eUSKobarometro (mayo 2018), Estudio Periódico de la Opinión Pública Vasca, Universidad del País Vasco, [consultado el 09/07/2021] <URL: dc4827dcfdebec8a2159e5d1940ca764.pdf (epimg.net)>

José FERNÁNDEZ ALBERTOS, Amparo GONZÁLEZ FERRER, Ignacio JURADO, Víctor LAPUENTE GINÉ, Sebastián LAVEZZOLO, Sandra LEÓN, Ferrán MARTíNEZ I COMA, Lluís ORRIOLS, Alberto PENADÉs, Marta ROMERo e Ignacio URGUZU SANCHO (eds.), Aragón es nuestro Ohio. Así votan los españoles, Madrid, El Hombre del Tres, 2015. 
Gaizka FERNÁNDEZ SOLDEVILLA y Raúl LóPEZ ROMO, Sangre, votos, manifestaciones: ETA y el nacionalismo vasco radical 1958-2011, Madrid, Tecnos, 2012.

GOBIERNO VASCO, «Elecciones municipales en Euskadi» [on-line], [consultado en junio de 2019] <URL: https://www.euskadi.eus/elecciones/>.

Christophe GUILLY, La France périphérique, Paris, Flammarion, 2015.

Eric HOBSBAWM et Terence RANGER, L'invention de la tradition, Paris, Éditions Amsterdam, 2006 [1983].

Bert KLANDERMANS, «New Social Movements and Ressource Mobilization», Dieter Rucht (ed.), Research on Social Movements, Boulder, Westview, 1991, p. 17-46.

Arnaud MERCIER, «Mobilisation collective et limites de la médiatisation comme ressource», Olivier Fillieule (ed.), Sociologie de la protestation, Paris, L'Harmattan, 1993, p. 245-260.

Stéphane MICHONNEAU, «L'invention du "problème catalan"», La Vie des Idées [on-line], (abril 2010) [consultado el 9/06/2021] <URL: 20100406_michonneau (archives-ouvertes.fr)>.

Thomas Jeffrey MILLEY, «Les dynamiques d'adaptation linguistique et d'assimilation culturelle en Catalogne», Alicia Fernández García y Mathieu Petithomme (eds.), Les nationalismes dans l'Espagne contemporaine (1975-2011). Compétition politique et identités nationales, Paris, Armand Colin, 2012, p. 437-469.

Érik NEVEU, Sociologie des mouvements sociaux, Paris, La Découverte, 2015.

Manuelle PELOILLE, Serge BUJ y Cyril TREPIER, L'indépendance catalane en question, Paris, Atlande, 2018.

Mathieu PEтітномме, «Commémorer les gudaris d'hier pour légitimer la violence d'aujourd'hui», Pôle Sud, nº 41 (2015), p. 105-136.

Mathieu Peтiтhomme, Génération Podemos. Sociologie politique d'un parti indigné, Rennes, PUR, 2021.

Miguel Ángel SALGADO, «La batalla de Villareal: 30 de noviembre-24 de diciembre de 1936», Sancho el Sabio. Revista de cultura e investigación vasca [on-line], n 26 (2007), p. 179-211[consultado el 10/07/2021]

<URL: https://dialnet.unirioja.es/servlet/articulo?codigo=2287468>.

Isabelle SOMMIER, La violence révolutionnaire, Paris, Presses de Sciences-Po, 2008.

Marina SUBIRATS, «Una utopía disponible: La Cataluña independiente», Josep Ramoneda (ed.), Cataluña-España: ¿Qué nos ha pasado?, Barcelona, Galaxia Gutenberg, 2019, p. 20-33.

Cyril TRÉPIER, Géopolitique de l'indépendantisme en Catalogne, Paris, L'Harmattan, 2016.

Enric UCELAY-DA CAL, Breve historia del separatismo catalán, Barcelona, B. Penguin Random House Grupo Editorial, 2018.

Laia VICENS i Xavi TEDO, Operació Urnes, Barcelona, Columna, 2017.

\section{Artículos de periódico}

«Las sentencias por enaltecimiento del terrorismo se multiplican», El Diario [on-line], (actualizado el 21/04/2018) [consultado el 09/07/2021]<URL: Las sentencias por enaltecimiento del terrorismo se multiplican por cuatro desde que ETA dejó de matar (eldiario.es)>.

«El efecto "soufflé” y la volatilidad electoral», El País, 29/04/2015. 
«EH Bildu pide a los vascos que se pongan en pie como en Cataluña», El País, 21/02/2015.

«EH Bildu propone un proceso en tres fases hasta una Constitución vasca», El País, 24/01/2015.

«El presidente de Sortu pide a la Guardia Civil que se vaya de Euskadi», El País, 14/01/2015.

«Arraiz declara que defendió romper con el Estado y no la "lucha armada" de ETA», El País, 02/04/2014.

«Sortu aguarda su refundación», El País, 22/02/2014.

«El Tribunal Europeo de derechos humanos condena España por la doctrina Parot», El Mundo, $10 / 07 / 2012$.

«ETA anuncia el cese definitivo de su actividad armada», Gara, 20/10/2011.

«Los presos de ETA apoyan el acuerdo de Gernika», El País, 24/09/2011.

«Los presos disidentes de ETA urgen a abordar la reparación de las víctimas», El País, 23/9/2011.

\section{NOTAS}

1. Christophe GUILLY, La France périphérique, Paris, Flammarion, 2015.

2. Laurent DAVEZIES, Le nouvel égoïsme territorial, Paris, Le Seuil, 2015.

3. El artículo 92 de la Constitución de 1978 deja claro que un referéndum no puede ser convocado ni organizado para consultar solo a «una parte» de los ciudadanos: «1. Las decisiones políticas de especial trascendencia podrán ser sometidas a referéndum consultivo de todos los ciudadanos. 2. El referéndum será convocado por el Rey, mediante propuesta del presidente del Gobierno, previamente autorizada por el Congreso de los Diputados. 3. Una ley orgánica regulará las condiciones y el procedimiento de las distintas modalidades de referéndum previstas en esta Constitución». Cf. Artículo 92, Título III. De las Cortes Generales. Capítulo Segundo. De la elaboración de las leyes. Constitución Española de 1978. Otra cosa sería reformar la Constitución para permitir un referéndum en Cataluña. En un marco puramente jurídico, el referéndum sería posible en el marco de la actual Constitución, pero solamente consultando a todos los españoles.

4. Stéphane MICHONNEAU, "L'invention du "problème catalan"», La Vie des Idées [on-line], (abril 2010) [consultado el 9/06/2021] <URL : 20100406_michonneau (archives-ouvertes.fr) > .

5. Conviene precisar aquí que no establezco una continuidad histórica entre la Lliga Regionalista y CiU. Por ejemplo, muchos miembros de la Lliga apoyaron al franquismo, algo que de ningún modo se puede decir de los futuros fundadores de $\mathrm{CiU}$, declaradamente antifranquistas. Quiero sobre todo subrayar, como lo expongo claramente, que «el independentismo es un fenómeno marginal, situado políticamente a la izquierda, que surge en la historia de España en los periodos de crisis política», un factor común entre los años 1930 y 2010. Defiendo también que, en ambos casos, esta progresión se ha producido en detrimento de la corriente más liberal y conservadora del nacionalismo.

6. Thomas Jeffrey MILLEY, «Les dynamiques d'adaptation linguistique et d'assimilation culturelle en Catalogne», Alicia Fernández García y Mathieu Petithomme (eds.), Les nationalismes dans l'Espagne contemporaine (1975-2011). Compétition politique et identités nationales, Paris, Armand Colin, 2012, p. 437-469.

7. Por ejemplo, muchos inmigrantes latinoamericanos recién nacionalizados españoles con una ley aprobada por el gobierno socialista de José Luis Rodríguez Zapatero, se han sumado posteriormente a las filas del nacionalismo catalán. Este proceso de integración de los inmigrantes a la sociedad catalana a través del nacionalismo ha sido particularmente estudiado por Jean Thomas ARRIGHI DE CASANOVA, «Managing Immigration in a Multinational Context. Border 
Struggles and Nation-Building in Contemporary Scotland and Catalonia», Eve Hepburn y Ricard Zapata-Barrero (eds.), The Politics of Immigration in Multi-level states, Londres, Palgrave Mac Millan, 2014, p. 108-129.

8. Sobre estos asuntos $c f$., José FERNÁNDEZ ALBERTOS, Amparo GONZÁLEZ FERRER, Ignacio JURADO, Víctor LAPUENTE GINÉ, Sebastián LAVEZZolo, Sandra LEÓN, Ferrán MARTíNEZ I COMA, Lluís ORRIOLS, Alberto PENADÉs, Marta ROMERO e Ignacio URGUZU SANCHO (eds.), Aragón es nuestro Ohio. Así votan los españoles, Madrid, El Hombre del Tres, 2015, p. 151-160; Montserrat CLUA I FAINÉ, «Identidad y política en Cataluña: el auge del independentismo en el nacionalismo catalán actual», Quaderns-e de l'Institut Català d'Antropologia, vol. 2, nº 19 (2014), p. 79-99.

9. Marina SUBIRATS, «Una utopía disponible: La Cataluña independiente», Josep Ramoneda (ed.), Cataluña-España: ¿Qué nos ha pasado?, Barcelona, Galaxia Gutenberg, 2019, p. 20-33.

10. Mathieu PEтIтномme, Génération Podemos. Sociologie politique d'un parti indigné, Rennes, PUR, 2021.

11. Enrique GIL CALVo, «El efecto "soufflé” y la volatilidad electoral», El País, 29/04/2015.

12. Cyril TRÉPIER, Géopolitique de l'indépendantisme en Catalogne, Paris, L'Harmattan, 2016.

13. El gobierno español envió tres barcos que atracaron uno en el puerto de Barcelona, otro en Palamós y otro en Tarragona.

14. Desde 2017, se autodenominan Comités de Defensa de la República.

15. Laia VICENS i Xavi TEDO, Operació Urnes, Barcelona, Columna, 2017.

16. Manuelle PELOILLE, Serge BUJ y Cyril TREPIER, L'indépendance catalane en question, Paris, Atlande, 2018, p. 191.

17. Isabelle SOMmIER, La violence révolutionnaire, Paris, Presses de Sciences-Po, 2008, p. 19.

18. Érik NEVEU, Sociologie des mouvements sociaux, Paris, La Découverte, 2015, p. 23.

19. Jesús CASQUETE, «Abertzale sí, pero, ¿quién dijo de izquierda?», El Viejo Topo, nº 268 (2010), p. 15-19.

20. Mathieu pетітномме, «Commémorer les 'gudaris' d'hier pour légitimer la violence d'aujourd'hui», Pôle Sud, n 41 (2015), p. 105-136.

21. Eric HobSBAWm y Terence RANGER, L'invention de la tradition, Paris, Éditions Amsterdam, 2006 [1983], p. 15.

22. El Bizkargi Eguna, se celebra cada año el 3 de mayo o el domingo posterior en el monte Bizkargi cerca del pueblo de Larrabetzu, en la provincia de Vizcaya. Esta fiesta popular conmemora una batalla entre los gudaris nacionalistas y las tropas republicanas que formaban la armada vasca contra los requetés, los milicianos carlistas de Navarra organizados en torno a la Comunión Tradicionalista, ayudados por la aviación alemana. Esta batalla abrió el camino a las tropas franquistas, que tomaron Bilbao el 19 de junio de 1937, lo que supuso la disolución del gobierno autónomo vasco.

23. La segunda fiesta popular vinculada con la Guerra Civil, el Albertia Eguna, se festeja el primer domingo de julio y celebra la «batalla de Villareal» (30 noviembre-24 diciembre 1936) en torno al monte Albertia en Álava. Durante la Transición democrática, la celebración se transfirió al mes de julio por iniciativa del PNV y por razones climáticas, ilustrando la maleabilidad de las reconstrucciones históricas. Villareal estaba situada en una zona estratégica debido al control del ferrocarril en dirección de París, pero también a la existencia de tres carreteras en dirección de Vitoria desde Bilbao, Durango y Mondragón. La batalla provocó la muerte de 1000 republicanos y nacionalistas vascos y dejó 3300 heridos. El apoyo de 7000 falangistas enviados desde Madrid fue clave. Mientras el PNV celebra la batalla en general y la memoria de los soldados vascos, los nacionalistas radicales celebran más precisamente la muerte en el monte Albertia de 300 resistentes del batallón Euzko Indarra de ANV. Cf Jesús CASQUETE, En el nombre de Euskal Herria. La religión política del nacionalismo vasco radical, Madrid, Tecnos, 2009, p. 142; Miguel Ángel SALGADO, «La batalla de Villareal: 30 de noviembre-24 de diciembre de 1936», Sancho el Sabio. 
Revista de cultura e investigación vasca [on-line], $\mathrm{n}^{\circ} 26$ (2007), p. 179-211[consultado el 10/07/2021] <URL: https://dialnet.unirioja.es/servlet/articulo?codigo=2287468>.

24. Arnaud ESQUERRE y Gérôme TRUC, «Les morts, leurs lieux et leurs liens», Raisons Politiques, $\mathrm{n}^{\circ}$ 41 (2011), p. 7.

25. Bert KLANDERMANS, «New Social Movements and Ressource Mobilization», Dieter Rucht (ed.), Research on Social Movements, Boulder, Westview, 1991, p. 17-46.

26. Arnaud MERCIER, «Mobilisation collective et limites de la médiatisation comme ressource», Olivier Fillieule (ed.), Sociologie de la protestation, Paris, L'Harmattan, 1993, p. 256.

27. Gaizka FERNÁNDEZ SOLDEVILLA y Raúl LóPEZ ROMO, Sangre, votos, manifestaciones: ETA y el nacionalismo vasco radical 1958-2011, Madrid, Tecnos, 2012, p. 224-229.

28. «ETA anuncia el cese definitivo de su actividad armada», Gara, 20/10/2011.

29. En el sentido de una creencia casi trascendental en la legitimidad de la lucha por la independencia del País Vasco, una creencia que puede llegar a defender postulados ajenos a la realidad, como la legitimidad de la lucha armada. Sobre esta noción, $C f$. Jesús CASQUETE, «La religión de la patria», Claves de Razón Práctica, n²07 (2010), p. 40-46.

30. GOBIERNO VASCO, «Elecciones municipales en Euskadi» [on-line], [consultado en junio de 2019] <URL: https://www.euskadi.eus/elecciones/>.

31. Mikel ORMAZABAL, «Sortu aguarda su refundación», El País, 22/02/2014.

32. «EH Bildu pide a los vascos que se pongan en pie como en Cataluña», El País, 21/0/2/2015.

33. «EH Bildu propone un proceso en tres fases hasta una Constitución vasca», El País, $24 / 01 / 2015$.

34. Esta evolución tiene raíces históricas a partir de las conversaciones informales que tuvieron lugar entre 2001 y 2006 entre Otegi, entonces portavoz de Batasuna, y Jesús Eguiguren, presidente del Partido Socialista de Euskadi (PSE). Estos intercambios secretos sirvieron como punto de partida del fallido proceso de paz con ETA del gobierno de José Luis Rodríguez Zapatero. De hecho, en abril de 2013, los dos dirigentes vascos fueron galardonado con el premio Gernika por la Paz y la Reconciliación por «su aportación en la consecución de la Paz en Euskal Herria».

35. Más allá del caso Bateragune, la trayectoria de Otegi en su vida militante - como antiguo miembro de ETA-pm y luego ETA-m en 1984; preso encarcelado varias veces y durante más de 10 años; dirigente de Herri Batasuna y Batasuna en los años 1990 y luego participante activo en el proceso de disolución de ETA - pone de manifiesto el derecho a la reinserción social y al activismo político de los antiguos miembros de ETA que han cumplido su pena y aceptan las reglas del juego democrático. Un proceso bien estudiado por Antoni BATISTA, Adiós a las armas. Una crónica del final de ETA, Madrid, Debate, 2011.

36. «Los presos de ETA apoyan el acuerdo de Gernika», El País, 24/09/2011.

37. «Los presos disidentes de ETA urgen a abordar la reparación de las víctimas», El País, $23 / 09 / 2011$.

38. La «doctrina Parot» corresponde a una jurisprudencia del Tribunal Supremo que permitía mantener en detención a presos que podían teóricamente ser liberados. Condenada en julio 1987 y tras veinte años de reclusión, Inés del Río podía ser puesta en libertad en 2008. Pero el 2 de julio del 2008, la Audiencia Nacional decidió posponer su salida hasta junio de 2017, una decisión invalidada cuatro años más tarde por el Tribunal Europeo. Cf. María PERAL, «El Tribunal Europeo de derechos humanos condena España por la 'doctrina Parot», El Mundo, 10/07/2012.

39. Adrián ALMEIDA DÍEZ, «La hipótesis revolucionaria. Nacionalismo vasco y crítica a la modernidad», Araucaria. Revista Iberoamericana de Filosofía, Política, Humanidades y Relaciones Internacionales, año 22, n 43 (2020), p. 119-142.

40. «Las sentencias por enaltecimiento del terrorismo se multiplican», El Diario [on-line], (actualizado el 21/04/2018) [consultado el 09/07/2021] <URL: Las sentencias por enaltecimiento del terrorismo se multiplican por cuatro desde que ETA dejó de matar (eldiario.es)>. 
41. «El presidente de Sortu pide a la Guardia Civil que se vaya de Euskadi», El País, 14/01/2015.

42. "Arraiz declara que defendió romper con el Estado y no la "lucha armada" de ETA», El País, 02/04/2014.

43. eusкobarometro (mayo 2018), Estudio Periódico de la Opinión Pública Vasca, Universidad del País Vasco, [consultado el 09/07/2021] <URL: dc4827dcfdebec8a2159e5d1940ca764.pdf (epimg.net)>

44. Por ejemplo, el caso del grupo terrorista e independentista catalán Terra Lliure, activo desde 1978 hasta 1991, que cometió «entre 86 y 196 atentados terroristas según quien hace las sumas», y cuyo balance asciende a 5 víctimas mortales (4 de ellas miembros de la organización) y varias decenas de heridos. Esta organización nunca tuvo sin embargo un papel y un apoyo relevante en la sociedad catalana. Cf. Enric UCELAY-DA CAL, Breve historia del separatismo catalán, Barcelona, B. Penguin Random House Grupo Editorial, 2018, p. 213.

45. Entre mayo de 2009 y diciembre de 2012, el gobierno vasco fue dominado por el PSE, siendo lehendakari Patxi López.

\section{RESÚMENES}

Cet article propose une analyse de l'histoire du temps présent en Catalogne et au Pays basque, en cherchant à expliquer plus précisément les raisons des trajectoires divergentes de radicalisation du nationalisme d'une part, et de pacification et de sortie de la violence d'autre part. En effet, malgré un contexte macro-économique similaire marqué par les effets de la Grande Récession après 2008, l'essor sans précédent de l'indépendantisme en Catalogne n'a pas trouvé d'équivalent au Pays basque. À partir d'une analyse des principales caractéristiques des nationalismes catalan et basque, ainsi que des principales évolutions des quinze dernières années, l'article insiste sur l'importance d'un ensemble de facteurs économiques, institutionnels, culturels, historiques et politiques.

This article proposes an analysis of the present time history in Catalonia and the Basque country, trying to explain more precisely the reasons of divergent trajectories, of radicalization of nationalism on the one hand, and of pacification and exit from violence on the other hand. Indeed, in spite of a similar macro-economic context dominated by the effects of the Great Recession after 2008, the unprecedented rise of the pro-independence movement in Catalonia did not find any equivalent in the Basque country. On the basis of the analysis of the main characteristics of catalan and basque nationalisms, as well as of the main changes in the last fifteen years, this article insists on the importance of a set of economical, institutional, cultural, historical and political factors.

\section{ÍNDICE}

Mots-clés: nationalisme, indépendantiste, radicalisation, pacification, Catalogne, Pays basque Keywords: nationalism, pro-independence movement, radicalization, pacification, Catalonia, Basque country 
AUTOR

MATHIEU PETITHOMME

Université de Bourgogne/Franche-Comté 